\title{
An Online Focus Group Approach to e-Government Acceptance and Use
}

\author{
Soraia Nunes ${ }^{1}$, José Martins ${ }^{1,2}$, Frederico Branco ${ }^{1,2}$, Mijail Zolotov ${ }^{3}$ \\ ${ }^{1}$ Universidade de Trás-os-Montes e Alto Douro, Vila Real, Portugal \\ ${ }^{2}$ INESC TEC and UTAD, Vila Real, Portugal \\ ${ }^{3}$ NOVA, Information Management School \\ soraia_nunes13@hotmail.com,jmartins@utad.pt, fbranco@utad.pt, \\ mijail.naranjo@novaims.unl.pt
}

\begin{abstract}
The emergence and widespread use of Information and Communication Technologies enabled government agencies to develop their capacity for citizens interaction, hence providing better public services. These electronic services, typically known as e-Government, have been undergoing significant development over the last few years. Information technologies have become one of the central elements in electronic governance today, and probably they will outstand in the future too.

Despite the clear advantages inherent in e-Government services usage, the interaction rate between citizens and governments is still low and considered to be unsatisfactory. In order to understand which determinants may influence and trigger the adoption of e-Government services by civil society, a research methodology consisting of a theory-based qualitative validation, has been defined. This validation is performed by an Online Focus Group, where several experts were involved with the goal of reaching a set of remarkable considerations about potential determinants that can influence the use of eGovernment services.
\end{abstract}

Keywords: e-Government, IT Adoption, Transactional Web Platforms, Online Focus Group.

\section{Introduction}

This study fits in the field of research of Information Systems (IS) - in the systems of Electronic Governance (e-Government), more properly. This type of system has evolved due to advances in Information and Communication Technologies (ICT), which not only continue to provide a set of transformations in societies and their relations, but also create a dynamic relationship between governments and citizens, contributing to enlarge efficiency in the interaction processes between both parties and providing a fundamental communication channel between governments and citizens [1].

ICTs combined with Internet in public services have enabled the development of a more horizontal, collaborative, flexible and innovative public governance, enabling a 
better relationship between citizens and government [2][3]. This also has been taking an important role in Public Administration modernization and improving the quality of delivered electronic services [1]. Information Technology (IT) has become one of the central elements in public services administration and management, enabling electronic governance to occupy a prominent place in governance. The incorporation of IT allows, not only the internal efficiency of management actions, but also provides better quality in public services (to citizens, organizations, and business) [4].

Electronic governance should provide, by concept, a dynamic and efficient relationship between the public sector and citizens, which is the basis for the whole adoption process. The process itself should, in addition to the relationship between citizens and the public-sector simplification, have the ability to make their services equally available to all [5]. The need for investments, when implementing eGovernance systems, shouldn't be ignored, whether in security matters or in reliability and performance. Implementation strategies should always be put in place aiming to provide across-the-board support to all citizens, guaranteeing the confidentiality and transparency of the services [6].

E-Government is a key element in the modernization, and is typically used as an increasing mechanism for transparency and accountability, making governance more efficient, results-oriented and citizen-centred [7]. According to Manoharan [6], eGovernment has been gaining major importance in several countries, where the objective is the existence of a greater and better relationship between governments and society, through services and information that are available online. In Portugal, eGovernment systems have been important means supporting governance, to the point that ANACOM [8] indicates that the country has a better performance in providing services to society and reports that one in two citizens and four in five companies use these services.

Hence, considering the relevancy of e-Government for societies digital transformation, the following research proposes a set of factors, selected from existing literature, that according to a group of experts are those with the most probability of impacting the referred technologies adoption.

\section{Previous research on the topic}

E-Government services should be available in appropriate and accessible media for all citizens of a community. Although the population already adopts e-government services, specially the mandatory e-government services [9], the rate of interaction with governments is still low, leading to the failure of e-Government initiatives. However, those e-services must be accessible and appropriate for citizens to adopt them and meet the needs of each individual. Thus, the adoption of e-Government services by society is essential for increasing the adoption rate.

In order to contribute to the knowledge about the adoption of e-Government services and the collection of essential and important data a previous literature review on the e-government topic has been performed [10]. The objectives of that study were to identify relevant research, from the last decade, on the topic in hand. The study allowed to carry out a bibliographical research, at the international level, on the 
adoption of the e-Government services, contributing to the identification of the variables that influence the acceptance and the use of e-Government by the users. In summary, the referred study allowed to map the quantitative studies on e-Government adoption. Hence, Nunes, Martins, Branco, Gonçalves and Au-Yong-Oliveira [10] allowed to suggested possible paths for future research and contributed to the understanding of the evolution and the scenario of publications. Considering the previously mentioned, the present article contribute has been drawn from the conceptual contribute provided by refered authors, i.e. the set of variables addressed in the performed electronic focus group has been collected from the previous study.

\section{Presentation and Analysis of Results}

\subsection{Online Focus Group Conceptualization}

The Focus Group research method or, as the name indicates, discussion group, consist on gathering a group of experts with the main objective of having a dialogue and analysing the reactions on a certain subject, collecting a vast amount of qualitative information in a relatively short period of time. Despite its qualitative nature, thus the possible impact of different interpretations on its results, this method is very useful and widely used in several fields of research, namely in social sciences, information systems and other important areas [11][12][13].

The use of focus groups as a research technique represents an interesting alternative for the development of qualitative studies. Normally, focus groups involve experts who come together to discuss a specific topic and whose interaction is fully recorded and analysed [14][15]. When considering the influence of information technologies to all existing research methods and methodologies, especially the Internet, one can assume the virtual application of the method through a derivative named Online Focus Groups (OFGs). The benefits of this OFG method include the possibility of involving experts located in different places who still interact synchronously, using tools such as email, forums or through social networks sites [16], making the collection of the resulting significant and perceptible facts a complex task.

The use of OFGs is advantageous for this investigation mainly because it allows experts opinions to be collected via online survey, it can be attractive for participants who feel uncomfortable in personally expressing their view, it allows the access of people or professionals who have little free time to physically participate in a research, the interaction performed through the use of a computer thus reducing participants' anxiety and also guarantees the availability of basic materials for discussion [17]. While the OFG method may not be appropriate in all situations, there is the advantage of using the technologies to bring together a group of participants separated by distance in an online environment that encourages interactive discussion [18].

From this perspective, one of the study motivations is to inspire the use of online focus groups in qualitative research. 


\subsection{Characterization of Online Focus Group Participants}

The application of the online focus group method followed two steps. First, the OFG participants have been chosen to the point of reaching a multidisciplinary group of participants with various specialties and with professional activities such as microenterprise managers, higher education professors, directors of public administration services and ICT specialists.

Table I - Focus Group panel individual demographics.

\begin{tabular}{|c|c|c|c|c|c|c|c|c|}
\hline \multicolumn{3}{|c|}{ Education Level } & \multicolumn{3}{|c|}{ Professional Group } & \multicolumn{3}{|c|}{$\begin{array}{l}\text { Years of Professional } \\
\text { Experience (Years) }\end{array}$} \\
\hline 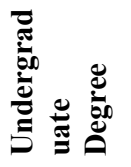 & 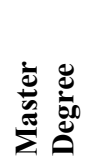 & $\stackrel{\text { I }}{\underline{a}}$ & $\frac{\mathscr{e}}{\stackrel{\mathscr{E}}{\tilde{E}}}$ & 兰泀 & 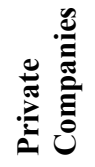 & cr & $\frac{0}{1}$ & $\stackrel{\Theta}{\Lambda}$ \\
\hline $44 \%$ & $29 \%$ & $27 \%$ & $43 \%$ & $43 \%$ & $14 \%$ & - & $43 \%$ & $57 \%$ \\
\hline
\end{tabular}

The selected experts were also located in different regions and had different academic qualifications (Table I). Second, an initial questionnaire, composed by all the variables resultant from the previous literature analysis, was given to all OFG participants and a private discussion forum was created to stimulate the group discussion.

\subsection{Description of the Data Collection Method}

According to the definition of the Online Focus Group method described above, it indicates that this method allows useful, important, and quality information to be obtained based on opinions disclosed by the group participants. In the present research context, the participants feedback was collected through an online questionnaire in which they were requested to classify the relative importance of each presented variable to e-Government adoption. The chosen data collection approach (Figure I) allowed to not only improve the OFG feedback organization and, subsequently, to reach the study purpose, i.e. reaching an initial assumption on the determinants of e-Government adoption.

For the present study, we used the 17 variables indicated by Nunes, Martins, Branco, Gonçalves and Au-Yong-Oliveira [10] as the most present in the existing literature.

$\sum \begin{array}{c}\text { Validation } \\ \text { Questionnaire }\end{array} \gg$ Data Collection $\left.\gg \begin{array}{c}\text { List of } \\ \text { Variables }\end{array} \gg \begin{array}{c}\text { Discussion of } \\ \text { Results }\end{array}\right\rangle$

Figure I - Representation of the stages.

For the accomplishment of the online validation questionnaire, the invitation of participation and the link of the respective survey for each participant was sent 
individually via email in order to guarantee their anonymity. In the email sent to the participants, was made a reference to the two-week time for the participants to answer the questionnaire.

In the posed questionnaire, for each inquired variable its definition was described in a short sentence, in case of any doubts about its meaning by the participants and they were requested to use a 7-point Likert scale, where level 1 would refer to the classification "Not Important" and level 7 would refer to the "Very Important" classification, to classify their perspective on the variable relative importance to the eGovernment adoption process.

\section{Results Analysis and Discussion}

\subsection{Online Focus Group Interactive Discussion}

After the stipulated time for participants to complete the initial questionnaire, the results discussion in the created forum was triggered, hence promoting constructive discussions with the experts for a deeper understanding on each of the posed variables. During the interactive discussion, individual requests have been made by the experts for including an additional three variables to the overall discussion (Trust on e-Government Infrastructure, Demographic Factors and Privacy Concerns), given their individual perception on their relative importance to the technology adoption process. This led to a final count of 20 variables that were included for inquiry in a second questionnaire sent to all OFG participants.

After the inclusion of the abovementioned variables for discussion, a set of very active discussions have been on their relative importance, to the point of the group (as a whole) assuming its inability to reach a formal consensus.

\subsection{Results analysis}

After the interactive discussion with the participants, all the data were gathered and later transformed into a table. This procedure allows the data collected analysis, at where the answers of the experts, regarding each variable and verifying which variables were classified as more important for the process of adoption of eGovernment (classification 7) and which were less important (classification 1).

The following table (Table II) presents statistical data obtained from an initial analysis to the second questionnaire results. It should be noted that the higher the average value of each a variable, the more it is considered important for the adoption of e-Government by the society.

According to the statistical analysis values presented in table II, a group of eleven variables can be observed, whose average classification is above 6.00 (2nd importance on the used Likert scale), representing those with the biggest relative importance, according to the OFG participants, to the e-Government adoption process. 
Table II - Mean values and standard deviation of each variable.

\begin{tabular}{lcc}
\hline Variables & Average & Standard Deviation \\
\hline Trust on e-Government Services & 6,86 & 0,35 \\
Security & 6,71 & 0,45 \\
Perceived Usefulness & 6,43 & 0,49 \\
Trust on the Internet & 6.43 & 0.73 \\
Perceived Ease of Use & 6.29 & 0,70 \\
System Quality & 6.29 & 0.70 \\
Trust on e-Government Infrastructure & 6,29 & 1.16 \\
Effort Expectancy & 6.14 & 1.12 \\
Privacy Concerns & 6.14 & 0.99 \\
Performance Expectancy & 6.00 & 0.93 \\
Perceived Risk & 6.00 & 1.07 \\
Use Behavior & 5.57 & 1.05 \\
Facilitating Conditions & 5.43 & 1.18 \\
Intention to Use & 5.43 & 0,73 \\
Culture & 5.14 & 1.25 \\
Attitude & 5.00 & 1,20 \\
Social Influence & 4.86 & 1.25 \\
Demographic Factors & 4.14 & 1.36 \\
\hline
\end{tabular}

All the experts with respect to the variable Trust on e-Government Services, had no doubt in classifying its degree of importance, being this the most influential factor of the entire list. During the OFG discussion there have been several variables that easily allowed for consensus but there were also a set of those who were not able to generate a consensual opinion on its importance to e-Government adoption process. Examples of these variables were the "Performance Expectation" and the "Perceived Risk". After reflecting on their meanings and their importance, the experts despite considering both as important, could not fully characterize one as definitively more important than the other. Nevertheless, the partial consensus is justified by the formation and professional experience of the experts which led them to agree with the direct gains arising from the use of the services in their activities. Regarding security and privacy, e-Government services must ensure the existence of secure environments that are able to guarantee levels of privacy in accordance with current legislation.

There was also a contradiction of views between the variables "Facilitation Conditions" and "Intention to Use", but eventually they reached an agreement with the degree of importance of each of those variables. The experts considered that it is extremely important that the system has the necessary organizational and technical infrastructure for its use.

Although there was some exchange of views on the degree of importance of some variables, after an exhaustive interactive discussion, the experts finally reached a consensus on the degree of importance of each variable. 


\section{Conclusions}

The results obtained with the implementation of a OFG, drawn from previous research on the topic [10], show some different assumptions from those present in existing literature. For instance, despite the Trust in e-Government Services is becoming less present in current research, from the OFG participants perspective this is the most relevant determinant for citizens acceptance and use of e-Government services.

The main intention of this study was the validation of the previous research contributes, i.e., the qualitative validation of the variables collected from existing scientific literature and assumed as the ones that, in theory, are the most relevant to the adopting e-Government.

By knowing the variables that might influence in a significant manner the adoption of e-Government services, governments can plan and develop its electronic government online services aligned with the presented acknowledgements. From our perspective, this will the referred technologies credibility and reliability and by consequence will trigger an increase on the citizens trust on the technology thus leading them to adopt the services and also to increase the rate of e-Government usage.

This study aimed to create a starting point for a greater awareness on the part of the public entities in the development and improvement of their digital platforms, taking into consideration the variables and their degrees of importance, in the rate of acceptance, adoption and use of the e-Government services.

\subsection{Limitations and Future Research}

Like most scientific studies, this one also identifies a set of limitations. The fact that there is a low reproducibility of the predictions based on the results obtained, the need to have sensitivity of the questionnaires results used for the collection of information, and the difficulty in assessing the degree of knowledge possessed by the participant group of the method used for the case study, are just a few that can be referred.

Future research may focus on developing a conceptual research model, composed by the variables resulting from the performed OFG, and evaluating it by performing an empirical study where the collected data should be evaluated using methods such as structural equations modelling [20][21] to acknowledge the strength of each conceptual determinants as drivers for users' intention to use and actual use of eGovernment services.

\section{References}

1. Bertot, J.C., Jaeger, P.T.: User-centered e-government: Challenges and benefits for government Web sites. Government Information Quarterly 23, 163-168 (2006)

2. Al Hujran, O., Aloudat, A., Altarawneh, I.: Factors influencing citizen adoption of egovernment in developing countries: The case of Jordan. International Journal of Technology and Human Interaction (IJTHI) 9, 1-19 (2013) 
3. Al-Hujran, O., Al-Debei, M.M., Chatfield, A., Migdadi, M.: The imperative of influencing citizen attitude toward e-government adoption and use. Computers in human Behavior 53, 189-203 (2015)

4. Lallmahomed, M.Z., Lallmahomed, N., Lallmahomed, G.M.: Factors influencing the adoption of e-Government Services in Mauritius. Telematics and Informatics (2017)

5. Peña-López, I.: UN e-government survey 2012. e-Government for the people. (2012)

6. Manoharan, A.: Active Citizen Participation in E-Government: A Global Perspective: A Global Perspective. IGI Global (2012)

7. Aggelidis, V.P., Chatzoglou, P.D.: Using a modified technology acceptance model in hospitals. International journal of medical informatics 78, 115-126 (2009)

8. ANACOM: E-Government - Portugal entre os melhores da Europa. (2011)

9. Chan, F.K., Thong, J.Y., Venkatesh, V., Brown, S.A., Hu, P.J., Tam, K.Y.: Modeling citizen satisfaction with mandatory adoption of an e-government technology. (2011)

10. Nunes, S., Martins, J., Branco, F., Gonçalves, R., Au-Yong-Oliveira, M.: An initial approach to e-government acceptance and use: A literature analysis of e-Government acceptance determinants. In: 2017 12th Iberian Conference on Information Systems and Technologies (CISTI), pp. 1-7. (2017)

11. Gonçalves, R., Martins, J., Pereira, J., Cota, M., Branco, F.: Promoting e-commerce software platforms adoption as a means to overcome domestic crises: the cases of Portugal and Spain approached from a focus-group perspective. Trends and Applications in Software Engineering, pp. 259-269. Springer (2016)

12. Atkinson, A., Bellis, M., Sumnall, H.: Young peoples' perspective on the portrayal of alcohol and drinking on television: findings of a focus group study. Addiction Research \& Theory 21, 91-99 (2013)

13. Anshari, M., Almunawar, M.N., Shahrill, M., Wicaksono, D.K., Huda, M.: Smartphones usage in the classrooms: Learning aid or interference? Education and Information Technologies 1-17 (2017)

14. Martins, A., Queirós, A., Rocha, N., Santos, B.: Avaliação de usabilidade: uma revisão sistemática da literatura. RISTI-Revista Ibérica de Sistemas e Tecnologias de Informação 31-43 (2013)

15. Gonçalves, R., Martins, J., Pereira, J., Au-Yong-Oliveira, M., Ferreira, J.: Accessibility levels of Portuguese enterprise websites: equal opportunities for all? Behaviour \& Information Technology 31, 659-677 (2012)

16. Jervaeus, A., Nilsson, J., Eriksson, L., Lampic, C., Widmark, C., Wettergren, L.: Exploring childhood cancer survivors' views about sex and sexual experiences-findings from online focus group discussions. European Journal of Oncology Nursing 20, 165$172(2016)$

17. Stewart, D., Shamdasani, P.: Online Focus Groups. Journal of Advertising 46, 48-60 (2017)

18. Kenny, A.J.: Interaction in cyberspace: an online focus group. Journal of advanced nursing 49, 414-422 (2005)

19. Alharbi, N., Papadaki, M., Dowland, P.: The impact of security and its antecedents in behaviour intention of using e-government services. Behaviour \& Information Technology 1-17 (2016)

20. Faqih, K.: An empirical analysis of factors predicting the behavioral intention to adopt Internet shopping technology among non-shoppers in a developing country context: Does gender matter? Journal of Retailing and Consumer Services 30, 140-164 (2016)

21. Oliveira, T., Alhinho, M., Rita, P., Dhillon, G.: Modelling and testing consumer trust dimensions in e-commerce. Computers in Human Behavior 71, 153-164 (2017)

22. Carter, L., Weerakkody, V., Phillips, B., Dwivedi, Y.: Citizen Adoption of EGovernment Services: Exploring Citizen Perceptions of Online Services in the United States and United Kingdom. Information Systems Management 33, 124-140 (2016) 
23. Lee, C., Lei, U.: Adoption of e-government services in Macao. In: Proceedings of the 1 st international conference on Theory and practice of electronic governance, pp. 217220. ACM, (2007)

24. Israel, D., Tiwari, R.: Empirical study of factors influencing acceptance of egovernment services in India. Proceedings of the 5th International Conference on Theory and Practice of Electronic Governance, pp. 141-146. ACM, Tallinn, Estonia (2011) 